\title{
Distress among cancer patients attending rehabilitation in the community
}

\author{
Ann Kuo ${ }^{1}$
}

Received: 27 April 2021 / Accepted: 6 July 2021 / Published online: 17 July 2021

(c) The Author(s) 2021

\begin{abstract}
Purpose The aim of this study is to identify sources of distress among cancer patients attending rehabilitation in the community.

Methods Participants were 430 patients recruited from a cancer rehabilitation center in Singapore between 2017 and 2018 , who had rated their distress using the distress thermometer (DT) and indicated associated problems on the problem list. Chisquare tests were used to detect differences in the reported symptoms among three age groups. Exploratory factor analysis was used to identify symptom clusters. Partial correlational analysis was then performed to examine the relationship between distress, symptom clusters, and age controlling for gender and cancer type.

Results About $30 \%$ of the participants reported distress $\geq 5$ on the DT (mean 3.3 \pm 2.5 ), and the mean number of problems endorsed was $8 \pm 6$. A higher total number of reported problems $(r=.63)$ and younger age $(r=-.21)$ were associated with increased distress. The younger age group also reported more problems surrounding emotions, finance, work/school, children-related issues, and physical symptoms such as sleep and nausea. Of the 12 factors identified, 9 psychosocial and physical symptom clusters correlated with distress ( $r$ ranging from .12 to .41 ). All results were statistically significant after adjustment $(p \leq 0.05)$.

Conclusion Younger survivors are more at risk of distress and report greater role functioning concerns related to childcare, partner relationship, and work participation. Age-tailored and multimodal interventions may be necessary to adequately address age-related differences and help coordinate management of multiple symptom clusters across physical and psychosocial concerns.
\end{abstract}

Keywords Distress $\cdot$ Cancer rehabilitation $\cdot$ Community $\cdot$ Age $\cdot$ Symptom clusters

\section{Introduction}

Although distress level has been found to decline with time, unmet psychosocial needs and physical symptoms may emerge along the cancer trajectory (such as treatmentinduced side effects, recurrence, and advanced disease) and lead to enduring distress among cancer survivors $[1,2]$. Continual elevated level of distress has also been reported in cancer survivors 5 years post-cancer treatment and diagnosis, suggesting that distress and its associated problems may evolve or remain unresolved, requiring further intervention [3]. Conducting distress screening in the community is,

Ann Kuo

ann_kuo@singaporecancersociety.org.sg

1 Cancer Rehabilitation Services, Singapore Cancer Society, Singapore, Singapore therefore, necessary to help identify distressed cancer survivors for treatment through appropriate referrals to services and by providing effective management strategies to address underlying concerns [4-6].

The National Comprehensive Cancer Network's Distress Thermometer (DT) is developed to screen for distress, and a cut-off score has been used to indicate the need to intervene, informed by a 39-item Problem List (PL) [7]. Optimal cut-off score varies across cultures, clinical settings, cancer stages, and types; a cut-off score of 4 or 5 on the DT is generally recommended [8-10]. The accompanied PL items have been used to ascertain key concerns that may have perpetuated distress. Problems that most contributed to distress include emotional issues (particularly worry) and insurance/financial challenges which evidenced the need to provide emotional and financial counseling; the more commonly endorsed physical symptoms associated with distress 
are fatigue and sleep, indicating necessity for education and further rehabilitation [10-12].

Distress and symptom experiences have been observed to vary by age group [13-15]. Younger survivors are more likely to report higher distress and more depressive symptoms than older survivors $[16,17]$. In addition, patients who are younger may indicate more pain, sexual, and work/ school issues, while older patients may present with nutrition, shortness of breath, and mobility concerns [14, 18, 19]. In a sample of patients undergoing active cancer treatment, the percentage of patients reporting common symptoms like worry, fatigue, sleep, and pain was also found to be significantly lower in the older age group [19]. Age-related differences in distress rating, the type, and frequency of problems reported may help to underscore the importance of attending to disparate needs of cancer survivors across the life span.

Some of the cancer-related symptoms co-occur and have the potential to interact, leading to greater distress $[14,20]$. Symptom clusters that consist of two or more related concurrent symptoms may arise due to the disease, its treatment, or exacerbation from a triggering symptom [21]. Some of the symptom clusters include the psychoneurological cluster comprising of insomnia, fatigue, depression, pain, and cognitive disturbance; the gastrointestinal cluster involving nausea and vomiting; and the emotional cluster encompassing anxiety and depression [22, 23]. Identifying concurrent symptoms and prioritizing strategies to address possible underlying mechanism may help reduce distress and simplify management of multiple problems [20].

At present, the types of problems faced by cancer patients attending rehabilitation in the community and their relationships to distress are not well-established. Specifically, the extent to which age-related differences and symptom clusters affect these cancer survivors remains uncertain. This study aims to identify sources of distress using the problem list endorsed by cancer patients and examine the impact of age and symptom clusters on distress rating for the purpose of recommending appropriate intervention strategies and management of distress in community cancer rehabilitation.

\section{Methods}

The study design was a retrospective analysis of cross-sectional baseline data collected between 2017 and 2018 at a cancer rehabilitation center based in a community outpatient setting in Singapore. Exemption from ethics approval was granted by the institutional review board from the Agency for Integrated Care. All participants had consented to the collection and use of their data for research and development purposes, in compliance with the Singapore Personal Data Protection Act 2012, prior to completing the DT and the PL.

\section{Participants}

Research participants were 430 cancer patients, predominantly female and with breast cancer. Approximately $30 \%$ of the cancer patients reported a distress level of 5 or greater on the DT, and the mean number of problems reported on the PL was $8 \pm 6$ for the total sample; $10 \pm 6$ for patients $\leq 54$ years of age; $8 \pm 6$ for patients between 55 and 64 years of age; and $7 \pm 6$ for patients $\geq 65$ years of age. Characteristics of the participants are shown in Table 1. Patients with cognitive or severe visual and hearing impairment were excluded. The majority of the participants were able to complete the self-administered questionnaire with minimal or no assistance.

\section{Procedure}

The DT and the PL were administered during initial admission into the cancer rehabilitation program as part of routine screening. The participants completed the questionnaire in the presence of a staff to answer any questions, and assistance was provided for participants who were illiterate.

Table 1 Characteristics of cancer patients $(n=430)$

\begin{tabular}{|c|c|c|}
\hline Variable & Range & Mean \pm SD \\
\hline Age & $28-90$ & $60.0 \pm 11.1$ \\
\hline Distress (total sample) & $0-10$ & $3.3 \pm 2.5$ \\
\hline$\leq 54$ years $(n=134)$ & & $4.0 \pm 2.5$ \\
\hline $55-64$ years $(n=137)$ & & $3.2 \pm 2.6$ \\
\hline$\geq 65$ years $(n=152)$ & & $2.7 \pm 2.4$ \\
\hline Low distress & $0-4$ & $1.9 \pm 1.4$ \\
\hline High distress & $5-10$ & $6.5 \pm 1.4$ \\
\hline Number of problems endorsed & $0-32$ & $8 \pm 6$ \\
\hline Variable & $N$ & Percentage \\
\hline \multicolumn{3}{|l|}{ Gender } \\
\hline Female & 291 & 67.7 \\
\hline Male & 139 & 32.3 \\
\hline \multicolumn{3}{|l|}{ Cancer type } \\
\hline Breast & 200 & 46.5 \\
\hline Prostate & 80 & 18.6 \\
\hline Colorectal & 43 & 10.0 \\
\hline Gynecologic & 25 & 5.8 \\
\hline Lung & 21 & 4.9 \\
\hline Blood & 16 & 3.7 \\
\hline Head and neck & 14 & 3.3 \\
\hline Others & 31 & 7.2 \\
\hline \multicolumn{3}{|l|}{ Distress rating } \\
\hline$\geq 4$ & 175 & 40.7 \\
\hline$\geq 5$ & 132 & 30.7 \\
\hline
\end{tabular}




\section{Instrument}

Distress was measured by the DT that required participants to indicate their level of distress experienced in the past week including today from 0 (no distress) to 10 (extreme distress). The validity of the DT for distress screening using the Singapore cancer population was established; a cut-off score of 5 on the DT was shown to have the best sensitivity (0.88) and specificity (0.81) [10].

Distress symptoms were determined using the PL with the participants answering yes or no to a list of 39 items related to practical, family, emotional, spiritual/religious, and physical problems that they encountered within the past week including today. Internal consistency was found to be adequate using this study sample (Cronbach's alpha $=0.88$ ).

\section{Statistical analysis}

Descriptive analysis was employed to compare the frequency of commonly reported problems among three groups of cancer patients ( $\leq 54$ years of age; $55-64$ years of age; and $\geq 65$ years of age). Chi-square tests were used to assess differences in the proportions of various reported problems across three age groups. The Spearman's rank-order correlation analysis was also conducted to examine the relationship between distress rating and the problems/symptoms reported.

Appropriateness of the data for exploratory factor analysis (EFA) was determined by the Kaiser-Meyer-Olkin measure of sampling adequacy $(\mathrm{KMO}>0.60)$ and a significance of $\alpha<0.05$ on the Bartlett's test of sphericity. The number of factors to be extracted was based on an eigenvalue $>1$, the scree plot, and attaining a total variance of approximately $60 \%$. Items on the PL that did not load well on any of the factors (factor loading <0.30) and with low communalities $(<0.40)$ would be removed. Principal component analysis with orthogonal rotation (equamax) was performed to help simplify interpretation of the symptom factors. Factor scores were generated using regression method; bivariate and partial correlation analyses were conducted to further examine the relationship among symptom factors/clusters, distress, total number of items endorsed on the PL, and age, controlling for gender and cancer type.

All analyses were performed using IBM SPSS Statistics for Windows, Version 26.0 (Armonk, NY: IBM Corp) and conducted at the 0.05 significance level.

\section{Results}

Table 2 shows the relationship between distress and the reported symptoms ranked by the most distressing symptoms from emotions, loss of interest in usual activities, finance, and work or school concerns to change in urination. Among the physical symptoms, fatigue, sleep, difficulty with bathing and dressing, memory, and breathing issues were more associated with distress. Age-related differences were also revealed with the younger age group ( $\leq 54$ years of age) reporting more problems surrounding emotions, finance, work/school, children-related issues, and physical symptoms such as sleep and nausea. Change in urination was more frequently reported by the oldest age group ( $\geq 65$ years of age).

Exploratory factor analysis yielded 12 factors accounting for $59.9 \%$ of the total variance, presented in Table 3. Kaiser-Meyer-Olkin measure of sampling adequacy was found to be adequate at 0.85 , and the Bartlett's test of sphericity was also significant at $p<0.001$. Thirty-six PL items were retained. Distinct symptom clusters and one factor identified were (1) emotional (nervousness, fears, depression, and worry); (2) gastrointestinal (nausea, fevers, indigestion, and diarrhea); (3) fatigue (fatigue, sleep, and memory); (4) financial (housing, insurance/finance, and family health issues); (5) sensory (tingling, pain, and skin itch); (6) functional ability (bathing/dressing and getting around); (7) respiratory (breathing and nose congested); (8) relationship (deal with partner and children); (9) appearance (appearance and treatment decisions); (10) constipation (constipation, swelling, and mouth sores); (11) genitourinary (change in urination and sexual problems); and (12) childcare.

The zero-order and partial correlation coefficients for distress rating, age, and symptom clusters/factors are detailed in Table 4. A higher total number of reported problems $(r=0.63, p<0.01)$ and younger age $(r=-0.21, p<0.01)$ were associated with increased distress after controlling for gender and cancer type. Younger patients are also likely to endorse more problems $(r=-0.22, p<0.01)$. All symptom factors except sensory, constipation, and childcare correlated with distress, even after controlling for gender and cancer type. Emotional symptom cluster was the most distressing followed by financial, appearance, relationship, fatigue, functional ability, gastrointestinal, respiratory, and genitourinary symptom clusters. Fatigue, financial, appearance, and childcare correlated with age.

\section{Discussion}

Findings from this study suggest that between thirty and forty percent of cancer patients attending rehabilitation in the community may be at risk for distress, and these patients may often report multiple psychosocial and physical problems concurrently. The rate of distress among cancer patients in this sample appears comparable to prior studies that estimated between 25 to $40 \%$ of cancer survivors experiencing continual level of elevated distress post-cancer treatment $[3,24]$. In particular, the rate of distress using 
Table 2 Correlates of distress and the differences in frequency of reported symptoms across age groups

\begin{tabular}{|c|c|c|c|c|c|c|}
\hline \multirow[t]{2}{*}{ Symptoms } & \multirow[t]{2}{*}{$N(\%)$} & \multirow[t]{2}{*}{$\mathrm{DT}^{\mathrm{a}}$} & \multicolumn{3}{|c|}{ Age group } & \multirow[t]{2}{*}{$p$ value $^{\mathrm{b}}$} \\
\hline & & & $\leq 54(\%)$ & $55-64(\%)$ & $\geq 65(\%)$ & \\
\hline Worry & $224(53.0)$ & $.49 * *$ & 92 & 70 & 62 & $<.001$ \\
\hline Sadness & $130(30.7)$ & $.47 * *$ & 54 & 42 & 34 & $<.01$ \\
\hline Fears & 149 (35.2) & $.46^{* *}$ & 70 & 42 & 37 & $<.001$ \\
\hline Depression & 99 (23.4) & $.44 * *$ & 41 & 29 & 29 & $\mathrm{~ns}$ \\
\hline Nervousness & $115(27.2)$ & $.43 * *$ & 46 & 33 & 36 & ns \\
\hline Loss of interest & $89(21.0)$ & $.39 * *$ & 29 & 32 & 28 & ns \\
\hline Finance & $93(22.0)$ & $.33 * *$ & 39 & 31 & 23 & $<.05$ \\
\hline Fatigue & $226(53.4)$ & $.32 * *$ & 83 & 67 & 76 & ns \\
\hline Work/school & $70(16.5)$ & $.32 * *$ & 43 & 22 & 5 & $<.001$ \\
\hline Sleep & $196(46.3)$ & $.30 * *$ & 76 & 57 & 63 & $<.05$ \\
\hline Transportation & $48(11.3)$ & $.27 * *$ & 17 & 11 & 20 & $\mathrm{~ns}$ \\
\hline Housing & $43(10.2)$ & $.26^{* *}$ & 19 & 16 & 8 & $<.05$ \\
\hline Bath/dress & $36(8.5)$ & $.26 * *$ & 15 & 11 & 10 & ns \\
\hline Deal children & $34(8.0)$ & $.26^{* *}$ & 17 & 13 & 4 & $<.01$ \\
\hline Treatment decision & $73(17.3)$ & $.25^{* *}$ & 28 & 27 & 18 & ns \\
\hline Appearance & $64(15.1)$ & $.25^{* *}$ & 27 & 19 & 18 & $\mathrm{~ns}$ \\
\hline Memory & $178(42.1)$ & $.24 * *$ & 63 & 60 & 55 & ns \\
\hline Family health & $77(18.2)$ & $.24 * *$ & 29 & 31 & 17 & $<.05$ \\
\hline Breathing & 75 (17.7) & $.24 * *$ & 19 & 26 & 30 & ns \\
\hline Eating & $69(16.3)$ & $.24 * *$ & 27 & 21 & 21 & ns \\
\hline Deal partner & $52(12.3)$ & $.24 * *$ & 19 & 18 & 15 & ns \\
\hline Nausea & $42(9.9)$ & $.23 * *$ & 20 & 13 & 9 & $<.05$ \\
\hline Indigestion & $64(15.1)$ & $.22 * *$ & 24 & 25 & 15 & ns \\
\hline Pain & $180(42.6)$ & $.21 * *$ & 57 & 63 & 60 & ns \\
\hline Fevers & $25(5.9)$ & $.20 * *$ & 11 & 7 & 7 & ns \\
\hline Spiritual & $18(4.3)$ & $.20 * *$ & 9 & 7 & 2 & $\mathrm{~ns}$ \\
\hline Nose dry/congest & $65(15.4)$ & $.19 * *$ & 25 & 19 & 21 & ns \\
\hline Tingling & $191(45.2)$ & $.18 * *$ & 65 & 65 & 61 & ns \\
\hline Get around & $61(14.4)$ & $.17 * *$ & 22 & 14 & 25 & ns \\
\hline Feel swollen & $96(22.7)$ & $.16^{* *}$ & 39 & 24 & 33 & $\mathrm{~ns}$ \\
\hline Mouth sore & $26(6.1)$ & $.15^{* *}$ & 9 & 12 & 5 & ns \\
\hline Skin dry/itch & $169(40.0)$ & $.14 * *$ & 52 & 54 & 63 & ns \\
\hline Constipation & $76(18.0)$ & $.14 * *$ & 29 & 22 & 25 & ns \\
\hline Diarrhea & $36(8.5)$ & $.14^{* *}$ & 14 & 9 & 13 & ns \\
\hline Sexual & $34(8.0)$ & $.13^{* *}$ & 10 & 15 & 9 & ns \\
\hline Substance abuse & $6(1.4)$ & $.12^{*}$ & 2 & 1 & 3 & ns \\
\hline Childcare & $25(5.9)$ & $.10^{*}$ & 13 & 7 & 5 & $\mathrm{~ns}$ \\
\hline Ability to have child & $3(0.7)$ & .08 & 3 & 0 & 0 & $<0.05$ \\
\hline Change in urination & $55(13.0)$ & .06 & 6 & 17 & 32 & $<.001$ \\
\hline
\end{tabular}

Note: $D T$, distress thermometer; $n s$, not significant at $p<.05$ level. ${ }^{*} p<.05$. ${ }^{*} p<.01$

${ }^{\text {a }}$ Spearman's rank-order correlation

${ }^{\mathrm{b}}$ Chi-squared test

a cut-off score of $\geq 5$ on the DT is close to reported rates from the Netherlands using study samples of survivors with breast cancer measured at 12 to 15 -month post-diagnosis [2, 3]. The mean number of problems endorsed also parallels another study that reported $7.62 \pm 5.75$ mean items endorsed by cancer patients at risk for distress [4]. The rate of types of problems endorsed, sampled from a cancer rehabilitation clinic in Sweden, is similarly high for worry, fatigue, sleep, memory, pain, skin dryness/itch, and tingling [25]. Further, among the common problems reported by cancer survivors, emotional concerns, loss of interest in usual activities, finance, fatigue, work/school, and sleep may be the most 
Table 3 Symptom factors with factor loadings and communalities based on exploratory factor analysis

\begin{tabular}{|c|c|c|}
\hline Items & Communalities & Factor loadings \\
\hline \multicolumn{3}{|l|}{ Factor 1: emotional } \\
\hline Depression & .64 & .73 \\
\hline Sadness & .69 & .66 \\
\hline Fears & .66 & .61 \\
\hline Nervousness & .58 & .60 \\
\hline Loss of interest & .53 & .54 \\
\hline Worry & .58 & .47 \\
\hline \multicolumn{3}{|l|}{ Factor 2: gastrointestinal } \\
\hline Nausea & .60 & .67 \\
\hline Transportation & .57 & .65 \\
\hline Fevers & .54 & .59 \\
\hline Indigestion & .59 & .59 \\
\hline Diarrhea & .53 & .39 \\
\hline \multicolumn{3}{|l|}{ Factor 3: fatigue } \\
\hline Fatigue & .57 & .60 \\
\hline Sleep & .56 & .58 \\
\hline Memory & .53 & .55 \\
\hline Work/school & .67 & .49 \\
\hline \multicolumn{3}{|l|}{ Factor 4: finances } \\
\hline Housing & .68 & .76 \\
\hline Insurance/financial & .63 & .66 \\
\hline Family health issues & .47 & .49 \\
\hline \multicolumn{3}{|l|}{ Factor 5: sensory } \\
\hline Tingling & .55 & .68 \\
\hline Pain & .57 & .67 \\
\hline Skin dry/itch & .50 & .51 \\
\hline \multicolumn{3}{|c|}{ Factor 6: functional ability } \\
\hline Bath/dress & .71 & .81 \\
\hline Get around & .67 & .76 \\
\hline \multicolumn{3}{|l|}{ Factor 7: respiratory } \\
\hline Breathing & .65 & .77 \\
\hline Nose dry/congest & .64 & .59 \\
\hline Eating & .55 & .44 \\
\hline \multicolumn{3}{|l|}{ Factor 8: relationship } \\
\hline Deal with partner & .68 & .75 \\
\hline Deal with children & .63 & .72 \\
\hline \multicolumn{3}{|l|}{ Factor 9: appearance } \\
\hline Appearance & .65 & .77 \\
\hline Treatment decisions & .47 & .34 \\
\hline \multicolumn{3}{|l|}{ Factor 10: constipation } \\
\hline Constipation & .53 & .67 \\
\hline Feeling swollen & .53 & .47 \\
\hline Mouth sores & .65 & .42 \\
\hline \multicolumn{3}{|l|}{ Factor 11: genitourinary } \\
\hline Change in urination & .71 & .79 \\
\hline Sexual problems & .67 & .62 \\
\hline Factor 12: childcare & .60 & .73 \\
\hline
\end{tabular}

Table 4 Relationship among distress, age, and symptom clusters/factors, adjusting for gender and cancer type $(N=430)$

\begin{tabular}{|c|c|c|c|c|}
\hline \multirow[t]{2}{*}{ Variable } & \multicolumn{2}{|l|}{ DT } & \multicolumn{2}{|l|}{ Age } \\
\hline & Zero-order & Partial & Zero-order & Partial \\
\hline Emotional & $.40^{* *}$ & $.41 * *$ & -.10 & -.09 \\
\hline Gastrointestinal & $.17 * *$ & $.16^{* *}$ & -.03 & -.03 \\
\hline Fatigue & $.22 * *$ & $.21 * *$ & $-.16^{* *}$ & $-.14^{*}$ \\
\hline Financial & $.24 * *$ & $.25^{* *}$ & $-.14 * *$ & $-.16^{* *}$ \\
\hline Sensory & .07 & .06 & -.04 & -.05 \\
\hline Functional ability & $.20 * *$ & $.20 * *$ & .03 & .03 \\
\hline Respiratory & $.15^{* *}$ & $.15^{* *}$ & -.03 & -.03 \\
\hline Relationship & $.22 * *$ & $.21 * *$ & -.10 & -.08 \\
\hline Appearance & $.23 * *$ & $.23 * *$ & $-.24 * *$ & $-.25^{* *}$ \\
\hline Constipation & .00 & 0.01 & .01 & .04 \\
\hline Genitourinary & .08 & $.12 *$ & $.16^{* *}$ & .08 \\
\hline Childcare & .07 & -.07 & $-.17 * *$ & $-.15^{* *}$ \\
\hline
\end{tabular}

Note: $D T$, distress thermometer. $P L$, problem list, ${ }^{*} p<.05$. ** $p<.01$

distressing, evidencing the need for a holistic approach in cancer rehabilitation to deal with a mixed array of psychosocial and physical problems [26].

Younger cancer patients may be more at risk of distress, presenting with a greater mean distress rating and higher total number of reported problems compared to older cancer patients. Salient age-related psychosocial problems appear to surround (1) negative emotions; (2) employment and finances; (3) appearance; and (4) family relationships especially in dealing with children [27-29]. Having multiple role demands that are specific to a younger age (e.g., parenting young children, completing education, establishing career and finances, and managing marital relationship) may have contributed to greater distress [28]. As this study sample consists predominantly of women with breast cancer, some younger survivors may also be more concerned with body image and attractiveness after surgery and mastectomy, further affecting their emotions and the quality of their intimate relationship [30]. In addition, breast cancers in women under 40 years of age tend to be diagnosed at a later stage, presenting with more aggressive features and poorer outcomes, thus potentially leading to heightened distress. [31] Besides providing early support, education, and counseling services to this high-risk younger group, rehabilitation interventions should address the impact of cancer on patients' role functioning related to family life, partner relationship, and work participation as these problems are more commonly reported in distressed younger survivors [28].

Several symptom clusters are related to distress with the emotional symptom cluster appearing to be the most distressing. Emotional symptom cluster has also been shown to be the most burdensome over time compared to other symptom clusters and significantly attenuate the health status and 
quality of life of breast cancer survivors [32]. Losing interest in activity is a major hallmark of depression, suggesting that emotional issues may be accompanied by a reduction in activity participation. A prior study reported an average of $12 \%$ reduction in activity level especially in high physical demand leisure and social activities among older cancer survivors [33]. Despite performing fewer activities, cancer survivors may prefer to focus their resources on more enjoyable, creative, and meaningful engagements to help alleviate their mood [33]. Activity-focused rehabilitation that engages cancer survivors in a process of goal setting, evaluation, and problem-solving facilitates building of confidence in managing residual impairments [34]. Increased self-efficacy in coping with their symptoms during daily activities may in turn enhance cancer survivors' emotional well-being [35]. Supporting activity participation may serve as a key strategy to manage the emotional symptom cluster and promote better quality of life in cancer survivors [33, 36, 37].

Co-existing symptoms within a cluster often interact and elevate distress. For instance, having sleep disturbance may increase fatigue, and both sleep disturbance and fatigue affect cognitive function [38, 39]. Further, the presence of fatigue especially mental fatigue and cognitive dysfunction predisposes cancer survivors to having difficulties at work [40, 41]. Educating cancer patients on the relationship among co-occurring symptoms may lead to more effective management of the clustered symptoms and hence alleviate distress [20]. Multidisciplinary interventions combining psychoeducation, physical, and vocational components have demonstrated efficacy in supporting cancer survivors return to their worker role [42]. This study suggests a need to prioritize strategies to address the interaction of sleep, fatigue, and cognitive function within return to work or school interventions. Practical support may also be necessary to help deescalate distress for some symptom clusters. For example, cancer patients with gastrointestinal symptoms may experience a greater burden of distress commuting to clinic for chemotherapy compared to patients without such treatment side effects [43]. The gastrointestinal symptom clustercommonly characterized by nausea and vomiting-significantly affect cancer patients' daily function and quality of life [44, 45]; addressing transportation barriers for cancer patients with ongoing treatments may thus be beneficial. Other practical support may include financial assistance. Financial hardship may arise not only from cancer treatment-related out-of-pocket costs, but also reduced income, missed work, and/or medical debt [46]. Findings from this study underscore the need to consider housing and health issues of other family members when assessing financial distress and providing financial aid as the economic impact of cancer often affects the whole family [47].

In simplifying management of symptom clusters, strategies may be prescribed based on their potential benefits in associated symptoms or across multiple symptom clusters [20]. For example, exercise has been shown to improve emotional well-being and concurrently help reduce fatigue and pain and enhance sleep and physical and cognitive function [48-50]. Some studies have attributed the development of symptom cluster to inflammatory mechanisms, and exercise has been found to downregulate proinflammatory cytokines and upregulate anti-inflammatory cytokines, hence providing beneficial effects across a wide spectrum of symptoms [51, 52]. Besides exercise, stress management delivered through various intervention strategies such as cognitive behavioral therapy, mindfulness practice, deep breathing, and relaxation training has demonstrated positive effects on emotional well-being, pain, and fatigue [46, 53-55]. To effectively manage distressrelated symptoms, multimodal interventions that combine strategies such as exercise, stress management, nutrition, and psychoeducation have evidenced promising results with significant symptom reduction across diverse symptom clusters [56, 57].

Despite some limitations, this study provides insight on the relationship of symptom clusters to distress among cancer survivors to further understand their rehabilitation needs in the community setting. This study is limited by not accounting for socioeconomic status, stage of cancer, and the type of treatment received as these factors are also related to distress [58]. In addition, the problem list items are inadequate to cover issues faced by patients with different types of cancer, items such as swallowing difficulty and dry mouth related to head and neck cancer are not considered. In addition, some problem list items may be ambiguous, such as eating and feeling swollen. Eating may be related to dietary concern, loss of appetite, and/or feeding issue. Patients with poor appetite may not report on eating if they interpret eating as more of a feeding difficulty. Likewise, patients with lymphedema concern are less likely to endorse on the item feeling swollen as feeling swollen may also mean swelling and inflammation or bloating. Future studies should examine (1) the occurrence of symptom clusters based on a refined problem list that include clearly worded items relevant to common cancer types and (2) the relationship among co-existing symptoms for specific age group controlling for socioeconomic status, stage of disease, and treatment received.

In summary, cancer survivors, who are in distress, are more likely to experience multiple symptoms across physical and psychosocial domains. Younger survivors may be more at risk of distress with multiple roles to fulfill. Recognizing concurrent symptoms and providing coordinated rehabilitation strategies to manage across symptom clusters for different age groups are necessary to help reduce enduring distress among cancer survivors in the community. 
Acknowledgements The author thanks the staff from the Singapore Cancer Society Rehabilitation Center and the Research and Data Analytics Department for their contributions and support.

Author contribution Sole contributor in manuscript preparation.

Data availability N/A

Code availability N/A

\section{Declarations}

Ethics approval Exemption from ethical approval was granted by the Agency for Integrated Care Institutional Review Board as this retrospective study involved anonymous data.

\section{Consent to participate N/A}

\section{Consent for publication N/A}

Conflict of interest The author declares no competing interests.

Open Access This article is licensed under a Creative Commons Attribution 4.0 International License, which permits use, sharing, adaptation, distribution and reproduction in any medium or format, as long as you give appropriate credit to the original author(s) and the source, provide a link to the Creative Commons licence, and indicate if changes were made. The images or other third party material in this article are included in the article's Creative Commons licence, unless indicated otherwise in a credit line to the material. If material is not included in the article's Creative Commons licence and your intended use is not permitted by statutory regulation or exceeds the permitted use, you will need to obtain permission directly from the copyright holder. To view a copy of this licence, visit http://creativecommons.org/licenses/by/4.0/.

\section{References}

1. Sisler J, Chaput G, Sussman J, Ozokwelu E (2016) Follow-up after treatment for breast cancer: practical guide to survivorship care for family physicians. Can Fam Physician 62(10):805-811

2. Lo-Fo-Wong DN, de Haes HC, Aaronson et al (2016) Predictors of enduring clinical distress in women with breast cancer. Breast Cancer Res Treat 158(3):563-572. https://doi.org/10.1007/ s10549-016-3896-7

3. Admiraal JM, Hoekstra-Weebers J, Schröder CP et al (2020) Distress, problems, referral wish, and supportive health care use in breast cancer survivors beyond the first year after chemotherapy completion. Support Care Cancer 28(7):3023-3032. https://doi. org/10.1007/s00520-019-05030-6

4. VanHoose L, Black LL, Doty K et al (2015) An analysis of the distress thermometer problem list and distress in patients with cancer. Support Care Cancer 23(5):1225-1232. https://doi.org/ 10.1007/s00520-014-2471-1

5. Pirl WF, Fann JR, Greer JA et al (2014) Recommendations for the implementation of distress screening programs in cancer centers: report from the American Psychosocial Oncology Society (APOS), Association of Oncology Social Work (AOSW), and Oncology Nursing Society (ONS) joint task force. Cancer 120(19):2946-2954. https://doi.org/10.1002/cncr.28750

6. Fiszer C, Dolbeault S, Sultan S, Brédart A (2014) Prevalence, intensity, and predictors of the supportive care needs of women diagnosed with breast cancer: a systematic review. Psychooncology 23(4):361-374. https://doi.org/10.1002/pon.3432

7. Riba MB, Donovan KA, Andersen B et al (2019) Distress management, Version 3.2019, NCCN clinical practice guidelines in oncology. J Natl Compr Cancer Netw 17(10):1229-1249. https:// doi.org/10.6004/jncen.2019.0048

8. Sun H, Thapa S, Wang B, Fu X, Yu S (2020) A systematic review and meta-analysis of the distress thermometer for screening distress in Asian patients with cancer. J Clin Psychol Med Settings 28(2):212-220. https://doi.org/10.1007/s10880-020-09705-9

9. Donovan KA, Grassi L, McGinty HL, Jacobsen PB (2014) Validation of the distress thermometer worldwide: state of the science. Psychooncology 23(3):241-250. https://doi.org/10.1002/pon.3430

10. Lim HA, Mahendran R, Chua J, Peh CX, Lim SE, Kua EH (2014) The distress thermometer as an ultra-short screening tool: a first validation study for mixed-cancer outpatients in Singapore. Compr Psychiatry 55(4):1055-1062. https://doi.org/ 10.1016/j.comppsych.2014.01.008

11. McFarland DC, Shaffer KM, Tiersten A, Holland J (2018) Prevalence of physical problems detected by the distress thermometer and problem list in patients with breast cancer. Psychooncology 27(5):1394-1403. https://doi.org/10.1002/pon.4631

12. Chan A, Poon E, Goh WL et al (2018) Assessment of psychological distress among Asian adolescents and young adults (AYA) cancer patients using the distress thermometer: a prospective, longitudinal study. Support Care Cancer 26(9):32573266. https://doi.org/10.1007/s00520-018-4189-y

13. Syrowatka A, Motulsky A, Kurteva S et al (2017) Predictors of distress in female breast cancer survivors: a systematic review. Breast Cancer Res Treat 165(2):229-245. https://doi.org/10. 1007/s10549-017-4290-9

14. Thomas BC, Waller A, Malhi RL et al (2014) A longitudinal analysis of symptom clusters in cancer patients and their sociodemographic predictors. J Pain Symptom Manage 47(3):566578. https://doi.org/10.1016/j.jpainsymman.2013.04.007

15. Ritchie C, Dunn LB, Paul SM et al (2014) Differences in the symptom experience of older oncology outpatients. J Pain Symptom Manage 47(4):697-709. https://doi.org/10.1016/j. jpainsymman.2013.05.017

16. Naik H, Leung B, Laskin J et al (2020) Emotional distress and psychosocial needs in patients with breast cancer in British Columbia: younger versus older adults. Breast Cancer Res Treat 179(2):471-477. https://doi.org/10.1007/s10549-019-05468-6

17. Champion VL, Wagner LI, Monahan PO et al (2014) Comparison of younger and older breast cancer survivors and agematched controls on specific and overall quality of life domains. Cancer 120(15):2237-2246. https://doi.org/10.1002/cncr.28737

18. Avis NE, Levine B, Naughton MJ, Case DL, Naftalis E, Van Zee KJ (2012) Explaining age-related differences in depression following breast cancer diagnosis and treatment. Breast Cancer Res Treat 136(2):581-591. https://doi.org/10.1007/ s10549-012-2277-0

19. Cataldo JK, Paul S, Cooper B et al (2013) Differences in the symptom experience of older versus younger oncology outpatients: a cross-sectional study. BMC Cancer 13:6. https://doi. org/10.1186/1471-2407-13-6

20. Kwekkeboom KL (2016) Cancer symptom cluster management. Semin Oncol Nurs 32(4):373-382. https://doi.org/10.1016/j. soncn.2016.08.004

21. Aktas A (2013) Cancer symptom clusters: current concepts and controversies. Curr Opin Support Palliat Care 7(1):38-44. https://doi.org/10.1097/SPC.0b013e32835def5b

22. Fiorentino L, Rissling M, Liu L, Ancoli-Israel S (2011) The symptom cluster of sleep, fatigue and depressive symptoms in breast cancer patients: severity of the problem and treatment 
options. Drug Discov Today Dis Models 8(4):167-173. https:// doi.org/10.1016/j.ddmod.2011.05.001

23. Miaskowski C, Barsevick A, Berger A et al (2017) Advancing symptom science through symptom cluster research: expert panel proceedings and recommendations. J Natl Cancer Inst 109(4):djw253. https://doi.org/10.1093/jnci/djw253

24. Tuinman MA, Gazendam-Donofrio SM, Hoekstra-Weebers JE (2008) Screening and referral for psychosocial distress in oncologic practice: use of the distress thermometer. Cancer 113(4):870-878. https://doi.org/10.1002/cncr.23622

25. Ekman H, Pettersson A, Jakobsson L, Garmy P (2020) A cross-sectional study of distress: a cancer response. Nurs Open 7(3):850-856. https://doi.org/10.1002/nop2.460

26. Hellbom M, Bergelt C, Bergenmar M et al (2011) Cancer rehabilitation: a Nordic and European perspective. Acta Oncol 50(2):179-186. https://doi.org/10.3109/0284186X.2010.533194

27. Hubbeling HG, Rosenberg SM, González-Robledo MC et al (2018) Psychosocial needs of young breast cancer survivors in Mexico City. Mexico. PLoS One 13(5):e0197931. https://doi. org/10.1371/journal.pone.0197931

28. Christophe V, Duprez C, Congard A et al (2015) The subjective experience of young women with non-metastatic breast cancer: the Young Women with Breast Cancer Inventory. Health Qual Life Outcomes 13:73. https://doi.org/10.1186/ s12955-015-0273-x

29. Campbell-Enns H, Woodgate R (2015) The psychosocial experiences of women with breast cancer across the lifespan: a systematic review protocol. JBI Database Syst Rev Implement Rep 13(1):112-121. https://doi.org/10.11124/jbisrir-2015-1795

30. Baucom DH, Porter LS, Kirby JS, Gremore TM, Keefe FJ (2005) Psychosocial issues confronting young women with breast cancer. Breast Dis 23:103-113. https://doi.org/10.3233/ bd-2006-23114

31. Fredholm H, Eaker S, Frisell J, Holmberg L, Fredriksson I, Lindman H (2009) Breast cancer in young women: poor survival despite intensive treatment. PLoS One 4(11):e7695. https://doi. org/10.1371/journal.pone.0007695

32. KenneSarenmalm E, Browall M, Gaston-Johansson F (2014) Symptom burden clusters: a challenge for targeted symptom management. A longitudinal study examining symptom burden clusters in breast cancer. J Pain Symptom Manage 47(4):731741. https://doi.org/10.1016/j.jpainsymman.2013.05.012

33. Lyons KD, Lambert LA, Balan S, Hegel MT, Bartels S (2012) Changes in activity levels of older adult cancer survivors. OTJR Occup Participation Health 33(1):31-39. https://doi.org/10. 3928/15394492-20120607-02

34. Brick R, Skidmore E (2020) Optimizing cancer rehabilitation through activity-focused approaches. Semin Oncol Nurs 36(1):150985. https://doi.org/10.1016/j.soncn.2019.150985

35. Shelby RA, Edmond SN, Wren AA et al (2014) Self-efficacy for coping with symptoms moderates the relationship between physical symptoms and well-being in breast cancer survivors taking adjuvant endocrine therapy. Support Care Cancer 22(10):2851-2859. https://doi.org/10.1007/s00520-014-2269-1

36. Fleischer A, Howell D (2017) The experience of breast cancer survivors' participation in important activities during and after treatments. Br J Occup Ther 80(8):470-478. https://doi.org/10. 1177/0308022617700652

37. Newman RM, Alfano CM, Radomski MV et al (2019) Catalyzing research to optimize cancer survivors' participation in work and life roles. OTJR 39(4):189-196. https://doi.org/10.1177/ 1539449219844749

38. Henneghan AM, Carter P, Stuifbergan A, Parmelee B, Kesler S (2018) Relationships between self-reported sleep quality components and cognitive functioning in breast cancer survivors up to 10 years following chemotherapy. Psychooncology 27(8):1937-1943. https://doi.org/10.1002/pon.4745

39. Howell D, Oliver TK, Keller-Olaman S et al (2014) Sleep disturbance in adults with cancer: a systematic review of evidence for best practices in assessment and management for clinical practice. Ann Oncol 25(4):791-800. https://doi.org/10.1093/ annonc/mdt506

40. Islam T, Dahlui M, Majid HA et al (2014) Factors associated with return to work of breast cancer survivors: a systematic review. BMC Public Health 14(Suppl 3):S8. https://doi.org/10. 1186/1471-2458-14-S3-S8

41. Tan FL, Loh SY, Su TT, Veloo VW, Ng LL (2012) Return to work in multi-ethnic breast cancer survivors-a qualitative inquiry. Asian Pac J Cancer Prev 13(11):5791-5797. https:// doi.org/10.7314/apjcp.2012.13.11.5791

42. de Boer AG, Taskila TK, Tamminga SJ, Feuerstein M, FringsDresen MH (2015) Verbeek JH (2015) Interventions to enhance return-to-work for cancer patients. Cochrane Database Syst Rev 9:CD007569. https://doi.org/10.1002/14651858.CD007569. pub3

43. Syed ST, Gerber BS, Sharp LK (2013) Traveling towards disease: transportation barriers to health care access. J Community Health 38(5):976-993. https://doi.org/10.1007/ s10900-013-9681-1

44. Cherwin CH (2012) Gastrointestinal symptom representation in cancer symptom clusters: a synthesis of the literature. Oncol Nurs Forum 39(2):157-165. https://doi.org/10.1188/12.ONF. $157-165$

45. Ward Sullivan C, Leutwyler H, Dunn LB, Miaskowski C (2018) A review of the literature on symptom clusters in studies that included oncology patients receiving primary or adjuvant chemotherapy. J Clin Nurs 27(3-4):516-545. https://doi.org/10.1111/ jocn. 14057

46. Altice CK, Banegas MP, Tucker-Seeley RD, Yabroff KR (2016) Financial hardships experienced by cancer survivors: a systematic review. J Natl Cancer Inst 109(2):djw205. https://doi.org/ 10.1093/jnci/djw205

47. Carrera PM, Kantarjian HM, Blinder VS (2018) The financial burden and distress of patients with cancer: understanding and stepping-up action on the financial toxicity of cancer treatment. CA Cancer J Clin 68(2):153-165. https://doi.org/10.3322/caac. 21443

48. Kwekkeboom KL, Cherwin CH, Lee JW, Wanta B (2010) Mindbody treatments for the pain-fatigue-sleep disturbance symptom cluster in persons with cancer. J Pain Symptom Manage 39(1):126-138. https://doi.org/10.1016/j.jpainsymman.2009.05. 022

49. Jones LW, Alfano CM (2013) Exercise-oncology research: past, present, and future. Acta Oncol 52(2):195-215. https://doi.org/ 10.3109/0284186X.2012.742564

50. Schmitz KH, Campbell AM, Stuiver MM et al (2019) Exercise is medicine in oncology: engaging clinicians to help patients move through cancer. CA Cancer J Clin 69(6):468-484. https:// doi.org/10.3322/caac. 21579

51. Kwekkeboom KL, Tostrud L, Costanzo E et al (2018) The role of inflammation in the pain, fatigue, and sleep disturbance symptom cluster in advanced cancer. J Pain Symptom Manage 55(5):1286-1295. https://doi.org/10.1016/j.jpainsymman.2018. 01.008

52. Wood LJ, Weymann K (2013) Inflammation and neural signaling: etiologic mechanisms of the cancer treatment-related symptom cluster. Curr Opin Support Palliat Care 7(1):54-59. https:// doi.org/10.1097/SPC.0b013e32835dabe3

53. Gudenkauf LM, Antoni MH, Stagl JM et al (2015) Brief cognitive-behavioral and relaxation training interventions for breast 
cancer: a randomized controlled trial. J Consult Clin Psychol 83(4):677-688. https://doi.org/10.1037/ccp0000020

54. Jassim GA, Whitford DL, Hickey A, Carter B (2015) Psychological interventions for women with non-metastatic breast cancer. Cochrane Database Syst Rev 5:CD008729. https://doi.org/10. 1002/14651858.CD008729.pub2

55. Hayama Y, Inoue T (2012) The effects of deep breathing on 'tension-anxiety' and fatigue in cancer patients undergoing adjuvant chemotherapy. Complement Ther Clin Pract 18(2):9498. https://doi.org/10.1016/j.ctcp.2011.10.001

56. Jarden M, Nelausen K, Hovgaard D, Boesen E, Adamsen L (2009) The effect of a multimodal intervention on treatmentrelated symptoms in patients undergoing hematopoietic stem cell transplantation: a randomized controlled trial. J Pain Symptom Manage 38(2):174-190. https://doi.org/10.1016/j.jpainsymman.2008.09.005
57. Ester M, Culos-Reed SN, Abdul-Razzak A et al (2021) Feasibility of a multimodal exercise, nutrition, and palliative care intervention in advanced lung cancer. BMC Cancer 21(1):159. https://doi.org/10.1186/s12885-021-07872-y

58. Syrowatka A, Motulsky A, Kurteva S et al (2017) Predictors of distress in female breast cancer survivors: a systematic review. Breast Cancer Res Treat 165:229-245. https://doi.org/10.1007/ s10549-017-4290-9

Publisher's note Springer Nature remains neutral with regard to jurisdictional claims in published maps and institutional affiliations. 